\title{
Trends in yearly prevalence of third-generation cephalosporin and fluoroquinolone resistant Enterobacteriaceae infections and antimicrobial use in Spanish hospitals, Spain, 1999 to 2010
}

A Asensio (aasensio.hpth@salud.madrid.org) ${ }^{1}$, T Alvarez-Espejo² , J Fernandez-Crehuet ${ }^{3}$, A Ramos $^{2}$, J Vaque-Rafart ${ }^{4}$,

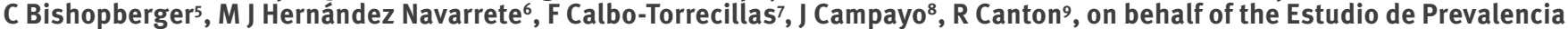
de las Infecciones Nosocomiales en España (EPINE) Working Group ${ }^{10}$

1. Department of Preventive Medicine, Hospital Universitario Puerta de Hierro, Madrid, Spain

2. Department of Internal Medicine, Hospital Universitario Puerta de Hierro, Madrid, Spain

3. Department of Preventive Medicine, Hospital Universitario Virgen de la Victoria, Universidad de Málaga, Málaga, Spain

4. Department of Preventive Medicine, Hospital Vall d’Hebron, Barcelona, Spain

5. Department of Preventive Medicine, Hospitales El Escorial/Guadarrama, San Lorenzo del Escorial, Madrid, Spain

6. Department of Preventive Medicine, Hospital Universitario Miguel Servet, Zaragoza, Spain

7. Department of Preventive Medicine, Hospital Universitario Carlos Haya, Málaga, Spain

8. Department of Preventive Medicine, Hospital General Universitario Reina Sofía, Murcia, Spain

9. Department of Microbiology, CIBER in Epidemiology and Public Health (CIBERESP), Hospital Universitario Ramón y Cajal and Instituto Ramón y Cajal de Investigación Sanitaria (IRYCIS), Madrid, Spain

10. Estudio de prevalencia de las infecciones nosocomiales en los hospitales españoles (EPINE), http://www.vhebron.net/ac/ preventiva/epine.htm. The members of the network are listed at the end of the article.

Asensio A, Alvarez-Espejo T, Fernandez-Crehuet J, Ramos A, Vaque-Rafart J, Bishopberger C, Hernández Navarrete MJ, Calbo-Torrecillas F, Campayo J, Canton $\mathrm{R}$, on behalf of the Estudio de Prevalencia de las Infecciones Nosocomiales en España (EPINE) Working Group. Trends in yearly prevalence of third-generation cephalosporin and fluoroquinolone resistant Enterobacteriaceae infections and antimicrobial use in Spanish hospitals, Spain, 1999 to 2010. Euro Surveill. 2011;16(40):pii=19983. Available online: http://www.eurosurveillance.org/ViewArticle.aspx?Articleld=19983

Article published on 6 October 2011

Escherichia coli, Klebsiella pneumoniae, and Enterobacter spp. are a major cause of infections in hospitalised patients. The aim of our study was to evaluate rates and trends of resistance to third-generation cephalosporins and fluoroquinolones in infected patients, the trends in use for these antimicrobials, and to assess the potential correlation between both trends. The database of national point prevalence study series of infections and antimicrobial use among patients hospitalised in Spain over the period from 1999 to 2010 was analysed. On average 265 hospitals and 60,000 patients were surveyed per year yielding a total of 19,801 E. coli, 3,004 K. pneumoniae and 3,205 Enterobacter isolates. During the twelve years period, we observed significant increases for the use of fluoroquinolones $(5.8 \%-10.2 \%$, p<0.001), but not for third-generation cephalosporins $(6.4 \%-5.9 \%$, $\mathrm{p}=\mathrm{NS}$ ). Resistance to third-generation cephalosporins increased significantly for $E$. coli $(5 \%-15 \%$, p<0.01) and for $K$. pneumoniae infections $(4 \%-21 \%$, p<0.01) but not for Enterobacter spp. (24\%). Resistance to fluoroquinolones increased significantly for $E$. coli $(16 \%-$ $30 \%$, p<0.01), for $K$. pneumoniae ( $5 \%-22 \%$, p<0.01), and for Enterobacter spp. (6\%-15\%, p<0.01). We found strong correlations between the rate of fluoroquinolone use and the resistance to fluoroquinolones, third-generation cephalosporins, or co-resistance to both, for $E$. coli $(\mathrm{R}=0.97$, $\mathrm{p}<0.01, \mathrm{R}=0.94$, $\mathrm{p}<0.01$, and $\mathrm{R}=0.96$, $\mathrm{p}<0.01$, respectively), and for $K$. pneumoniae $(R=0.92, p<0.01, R=0.91, p<0.01$, and $R=0.92, p<0.01$, respectively). No correlation could be found between the use of third-generation cephalosporins and resistance to any of the latter antimicrobials. No significant correlations could be found for Enterobacter spp.. Knowledge of the trends in antimicrobial resistance and use of antimicrobials in the hospitalised population at the national level can help to develop prevention strategies.

\section{Introduction}

Enterobacteriaceae are a major cause of infections in hospitalised patients [1]. Among them, the most frequent are Escherichia coli, Klebsiella pneumoniae, and Enterobacter spp. [2], with E. coli being the most frequent cause of bacteraemia, and community and hospital-acquired urinary tract infections (UTI) [3]. Bacteria of the genus Klebsiella frequently colonise the gastrointestinal tract, but can also be associated with opportunistic infections, including those of the urinary and respiratory tract. These organisms can spread rapidly among patients, mostly via the hands of hospital personnel, causing nosocomial outbreaks [4]. Within the Klebsiella genus, $K$. pneumoniae is the second leading cause of gram-negative bloodstream infections after E. coli [3]. In the family of the Enterobacteriaceae, Enterobacter spp. are also frequent pathogens that can cause opportunistic infections in hospitalised patients, especially in those who are immunocompromised or have mechanical ventilation support [1]. 
Fluoroquinolones and third-generation cephalosporins are classes of antibiotics frequently used for the treatment of infections caused by all of these organisms [1]. As a result of their extensive use, a continuous decline of the therapeutic effectiveness of these antimicrobial agents has been observed. This was predicted and seems unavoidable [5].

The aim of our study was to evaluate the rates and trends of resistance to different antimicrobials, particularly fluoroquinolones and third-generation cephalosporins, in the main Enterobacteriaceae causing nosocomial and community-acquired infections in hospitalised patients in Spain over a twelve year period (1999-2010), the trends in use of these antimicrobials within this period, and to assess a potential correlation between both trends.

\section{Methods}

Since 1990 , point prevalence study series of nosocomial and community-acquired infections among patients hospitalised in acute care facilities have been conducted in Spain (Estudio de prevalencia de las infecciones nosocomiales en los hospitales españoles - EPINE study). Each year in May, acute care hospitals in Spain are requested to voluntarily join the EPINE prevalence study. In some of the regions it is compulsory to conduct this study or any other prevalence audit. Participating hospitals fill a standardised questionnaire on each hospitalised patient as well as provide overall data on the hospital and the hospital's wards. Every participating hospital designates a hospital contact point as the person responsible for the survey at the hospital level and for communicating with the EPINE executive board.

Infection diagnosis relied on Centers for Disease Control and Prevention (CDC) case-definitions for nosocomial infections [6]. Infections that met the CDC criteria but developed outside of the hospital or in the first 48 hours upon admission were categorised as community-acquired infections. In addition to information on the source of the infection and the associated microorganisms, the patient forms collected from the hospitals included demographic data (age and sex), use of antimicrobial (as the number of patients receiving any antibiotic per 100 patients on the day of the survey), type of ward (general medical as opposed to a surgical, intensive care, paediatric or obstetric ward), and size of the hospital as measured by the number of beds (small: less than 200 beds, medium: 200-500 beds, large: more than 500 beds). The survey was performed by trained doctors, nurses and, in some hospitals, medical students. All the forms were revised for inconsistency and a percentage of them (10-15\%) were validated by the hospital contact point after revising medical records. Hospital validated forms were sent to an independent central analysis unit. A hospital report was sent back to every participating hospital to avoid possible disagreements before final integration of the collected results in a centralised database. We focused our analysis on resistance and antimicrobial use during the period from 1999 to 2010 .

Standard microbiological procedures were used by different institutions in their corresponding microbiology departments or laboratories that followed accreditation or certification procedures following local health authorities' requirements. Interpretive criteria (breakpoints) for susceptible, intermediate and resistant categories were those included in the Clinical and Laboratory Standards Institute guidelines $[7,8]$. Resistant isolates included both intermediate and resistant isolates as reported by the microbiological laboratory to the clinician. As not all the microbiology laboratories tested the same antibiotics in susceptibility testing, resistance rates were expressed as percentage of isolates that were resistant to fluoroquinolones (ciprofloxacin or levofloxacin) or thirdgeneration cephalosporins (ceftriaxone, cefotaxime or ceftazidime). No further characterisation of resistance mechanisms was recorded. Comparisons of characteristics of infections were made by Pearson's chi-square test. To determine significant trends over time of resistance rates and proportion of use, the CochranArmitage test was used. For correlation of antimicrobial use and the annual prevalence rates, Spearman correlation coefficient and regression coefficient were calculated. A p value $<0.05$ was considered significant. All calculations were performed with Stata/SE 9.0 statistical software.

\section{Results}

Between 1999 and 2010 an average of 265 hospitals per year (increasing from 233 in 1999 to 287 in 2010) participated in the EPINE survey yielding a sample of almost 60,000 hospitalised patients per year. Of a total of 303 hospitals participating in the survey at any given year, 230 took part in the entire twelve-year series.

During the period from 1999 to 2010 a total of 19,801 E. coli, 3,004 K. pneumoniae and 3,205 Enterobacter spp. isolates - including mainly E. cloacae $(72 \%)$ and E. aerogenes (18\%) species - causing nosocomial or community-acquired infections were recorded. The main characteristics of the corresponding infections for the period from 1999 to 2010 are displayed in Table 1. More than half of the infections occurred in patients aged over 65 years. $E$. coli infections were slightly more frequent in females, in contrast with $K$. pneumoniae or Enterobacter spp. infections ( $\mathrm{p}$ values<0.001). Overall, about three quarters of infections were identified in patients hospitalised in medical or surgical wards but for Enterobacter spp. infections the ratio medical/surgical ward was inversely (0.64) related to the ratio for $E$. coli or K. pneumoniae (1.42 and 1.56, respectively). Intensive care unit (ICU) infections accounted for $14 \%$ and $17 \%$ of $K$. pneumoniae and Enterobacter spp. infections respectively, in contrast to only $7 \%$ of $E$. coli infections. UTI was the most common localisation of infection for $E$. coli and for $K$. pneumoniae but not for 
Enterobacter spp.. Bloodstream infection represented $11.3 \%, 11.4 \%$ and $14 \%$ of the infection locations for each microorganism.

\section{Escherichia coli infections}

The characteristics of patients and hospitals where third-generation cephalosoporin resistance was found are shown in Table 2. Rates of resistance by type of ward ranged from $4.4 \%$ in gynecology and obstetrics to $13.3 \%$ in ICU patients, and by localisation of infection from $8.7 \%$ for UTI to $14.7 \%$ for respiratory infections. Information on fluoroquinolone resistance can also be found in table 2. Fluoroquinolone resistant $E$. coli infections were detected in patients from both sexes and all age groups seemed to be affected (although there appeared to be lower rates in age groups younger than
16 years old). Fluoroquinolone resistant $E$. coli could be community-acquired, but was more frequent in nosocomial infections, and in the largest hospitals. There were differences in the rates of fluoroquinolone resistance related to the type of ward and site of infection ranging from $5.4 \%$ in paediatric to $31.4 \%$ in medical wards and $32.6 \%$ in other hospital wards, and from $\mathbf{2 2 . 9} \%$ for surgical site wounds to $30.9 \%$ for respiratory tract infections (Table 2).

\section{Klebsiella pneumoniae infections}

Nosocomial infections as well as hospital size and type of ward, were associated with third-generation cephalosporin resistance. No difference for fluoroquinolone resistance was found by sex of the patients. High rates of fluoroquinolone resistant $K$. pneumoniae were found

\section{TABLE 1}

Main characteristics of patients infected by Escherichia coli, Klebsiella pneumoniae, or Enterobacter species in Spanish hospitals, Spain, 1999-2010 $(\mathrm{n}=672,362)$

\begin{tabular}{|c|c|c|c|c|c|c|}
\hline & \multicolumn{2}{|c|}{ Escherichia coli } & \multicolumn{2}{|c|}{ Klebsiella pneumoniae } & \multicolumn{2}{|c|}{$\begin{array}{l}\text { Enterobacter spp. } \\
(\text { Enterobacter cloacae) }\end{array}$} \\
\hline & $\mathrm{n}$ & $\%$ & $\mathrm{n}$ & $\%$ & $\mathrm{n}$ & $\%$ \\
\hline \multicolumn{7}{|l|}{ Sex } \\
\hline Male & 9,004 & 46.2 & 1,635 & 55.3 & $2,048(1,432)$ & $64.8(62.9)$ \\
\hline Female & 10,498 & 53.8 & 1,321 & 44.5 & $1,114(843)$ & $35.2(37.1)$ \\
\hline \multicolumn{7}{|l|}{ Age (in years) } \\
\hline$\leq 1$ & 1,165 & 5.9 & 178 & 5.9 & $178(137)$ & $5.6(6.0)$ \\
\hline $1-15$ & 567 & 2.9 & 40 & 1.3 & $48(38)$ & $1.5(1.7)$ \\
\hline $16-45$ & 2,116 & 10.7 & 399 & $13 \cdot 3$ & $470(322)$ & $14.7(14.0)$ \\
\hline $46-65$ & 3,963 & 20 & 724 & 24.2 & $802(570)$ & $25.1(24.8)$ \\
\hline$>65$ & 11,964 & 60.5 & 1,654 & 55.2 & $1,696(1,233)$ & $53.1(53.6)$ \\
\hline \multicolumn{7}{|l|}{ Localisation of infection } \\
\hline Urinary tract & 10,051 & 51.2 & 1,056 & 35.6 & $494(321)$ & $15.6(14.1)$ \\
\hline Surgical site & 2,908 & 14.8 & 384 & 12.9 & $876(683)$ & $27.7(30.0)$ \\
\hline Respiratory tract & 1,041 & 5.3 & 614 & 20.7 & $604(397)$ & $19.1(17.4)$ \\
\hline Bloodstream & 2,230 & 11.4 & 415 & 14.0 & $357(258)$ & $11.3(11.3)$ \\
\hline Other & 3,390 & 17.3 & 497 & 16.8 & $836(619)$ & $26.4(27.2)$ \\
\hline \multicolumn{7}{|l|}{ Source of infection } \\
\hline Community & 10,658 & 55.7 & 1,169 & 40.5 & $1,105(781)$ & $35.6(34.9)$ \\
\hline Nosocomial & 7,606 & 39.8 & 1,592 & 55.2 & $1,771(1,284)$ & $57.1(57.4)$ \\
\hline Nosocomial other admission ${ }^{b}$ & 870 & 4.5 & 123 & 4.3 & $224(172)$ & $7.2(7.7)$ \\
\hline \multicolumn{7}{|l|}{$\begin{array}{l}\text { Hospital size } \\
\text { (number of beds) }\end{array}$} \\
\hline$\ll 200$ & 5,568 & 28.1 & 688 & 23.0 & $697(482)$ & $21.8(20.9)$ \\
\hline $200-500$ & 8,030 & 406 & 1,256 & 41.9 & $1,297(952)$ & $40.5(41.3)$ \\
\hline$>500$ & 6,198 & 31.3 & 1,053 & 35.1 & $1,210(873)$ & $37.8(37.8)$ \\
\hline \multicolumn{7}{|l|}{ Ward } \\
\hline Medical & 8,950 & $45 \cdot 5$ & 1,352 & $45 \cdot 3$ & $914(643)$ & $28.8(28.1)$ \\
\hline Surgical & 6,314 & 32.1 & 867 & 29.1 & $1,422(1,062)$ & $44.7(46.4)$ \\
\hline Intensive care unit & 1,462 & 7.4 & 415 & 13.9 & $526(352)$ & $16.5(15.4)$ \\
\hline Gynecology and obstetrics & 635 & 3.2 & 47 & 1.6 & $48(30)$ & $1.5(1.3)$ \\
\hline Pediatric & 1,623 & 8.3 & 206 & 6.9 & $210(163)$ & $6.6(7.1)$ \\
\hline Other & 680 & 3.5 & 95 & 3.2 & $59(38)$ & $1.9(1.7)$ \\
\hline
\end{tabular}

a Numbers in parentheses are specific for Enterobacter cloacae.

b Patients hospitalised who, at the time of the survey, presented a nosocomial infection acquired during a previous admission in the same or another hospital. 
significantly associated to nosocomial infections, and the rates of fluoroquinolone resistance increased with the size of the hospital, or age of the patients, especially in patients older than one year. For the type of ward, a high rate of resistance was found in patients admitted to ICU (23.1\%), and the lowest rates of resistance were found in paediatric (2.9\%). For localisation of infection, UTI showed the highest rate of resistance (Table 2).

\section{Enterobacter species infections}

Nosocomial acquisition, ICU and pediatric wards, as well as bloodstream infections and UTI showed the highest prevalence of Enterobacter spp. resistance to

\section{TABLE 2}

Prevalence of resistance to third-generation cephalosporins and fluoroquinolones by microorganism and by characteristics of patient, infection, and hospital, Spain, 1999-2010

\begin{tabular}{|c|c|c|c|c|c|c|c|c|c|c|c|c|}
\hline & \multicolumn{4}{|c|}{ Escherichia coli } & \multicolumn{4}{|c|}{ Klebsiella pneumoniae } & \multicolumn{4}{|c|}{$\begin{array}{c}\text { Enterobacter spp. } \\
(\text { Enterobacter cloacae) }\end{array}$} \\
\hline & \multicolumn{2}{|c|}{$\begin{array}{l}\text { Third-generation } \\
\text { cephalosporin } \\
\text { resistance }\end{array}$} & \multicolumn{2}{|c|}{$\begin{array}{c}\text { Fluoroquinolone } \\
\text { resistance }\end{array}$} & \multicolumn{2}{|c|}{$\begin{array}{c}\text { Third-generation } \\
\text { cephalosporin } \\
\text { resistance }\end{array}$} & \multicolumn{2}{|c|}{$\begin{array}{c}\text { Fluoroquinolone } \\
\text { resistance }\end{array}$} & \multicolumn{2}{|c|}{$\begin{array}{l}\text { Third-generation } \\
\text { cephalosporin resistance }\end{array}$} & \multicolumn{2}{|c|}{$\begin{array}{l}\text { Fluoroquinolone } \\
\text { resistance }\end{array}$} \\
\hline & $\begin{array}{l}\text { Rate } \\
\text { (in \%) }\end{array}$ & $p$ value & $\begin{array}{l}\text { Rate } \\
\text { (in \%) }\end{array}$ & $p$ value & $\begin{array}{l}\text { Rate } \\
\text { (in \%) }\end{array}$ & $p$ value & $\begin{array}{l}\text { Rate } \\
\text { (in \%) }\end{array}$ & $\mathrm{p}$ value & $\begin{array}{l}\text { Rate } \\
\text { (in \%) }\end{array}$ & $p$ value & $\begin{array}{l}\text { Rate } \\
\text { (in \%) }\end{array}$ & $p$ value \\
\hline \multicolumn{13}{|l|}{ Sex } \\
\hline Male & 10.2 & 0.016 & 27.7 & $<0.001$ & 14.4 & 0.775 & $17 \cdot 9$ & 0.486 & $25.1(26.8)$ & $0.982(.961)$ & $10.3(10.6)$ & $\begin{array}{l}0.116 \\
(.314) \\
\end{array}$ \\
\hline Female & 9.2 & & 24.7 & & 14.0 & & 16.9 & & $25.1(27.0)$ & & $8.5(9.3)$ & \\
\hline \multicolumn{13}{|l|}{ Age (in years) } \\
\hline$\leq 1$ & 4.8 & $<0.001$ & 5.8 & $<0.001$ & 17.4 & 0.315 & 2.8 & $<0.001$ & $29.8(33.6)$ & $0.274(.206)$ & $3.9(5.1)$ & $\begin{array}{l}0.012 \\
(.033) \\
\end{array}$ \\
\hline $1-15$ & 7.1 & & 6.7 & & 5 & & 10.0 & & $18.8(21.1)$ & & $4.2(2.6)$ & \\
\hline $16-45$ & 8.4 & & 20.5 & & 13.3 & & 16.0 & & $25.7(28.9)$ & & $10.2(10.6)$ & \\
\hline $46-65$ & 9.8 & & 25.6 & & 13.8 & & 17.7 & & $23.1(24.6)$ & & 8.4 (8.9) & \\
\hline$>65$ & 10.5 & & 30.1 & & 14.4 & & 19.3 & & $25.5(26.8)$ & & $10.8(11.3)$ & \\
\hline \multicolumn{13}{|c|}{ Localisation of infection } \\
\hline Urinary tract & 8.7 & $<0.001$ & 26.7 & $<0.001$ & 16.6 & 0.065 & 22.7 & $<0.001$ & $28.3(32.4)$ & $0.002(.005)$ & $13.2(16.2)$ & $\begin{array}{l}0.015 \\
(.001) \\
\end{array}$ \\
\hline Surgical site & 10.5 & & 22.9 & & 15.1 & & 14.1 & & $25.9(26.1)$ & & $7.6(7.8)$ & \\
\hline Respiratory tract & 14.7 & & 30.9 & & 12.1 & & 14.5 & & $25.3(28.7)$ & & $10.3(10.1)$ & \\
\hline Bloodstream & 9.7 & & 25.1 & & 12.5 & & 14.0 & & $29.1(30.6)$ & & $8.1(8.5)$ & \\
\hline Other & 10.3 & & 26.7 & & 13.1 & & 15.9 & & $20.2(22.1)$ & & $10.0(10.5)$ & \\
\hline \multicolumn{13}{|l|}{ Source of infection } \\
\hline Community & 7.9 & $<0.001$ & 24.8 & $<0.001$ & 8.6 & $<0.001$ & 12.1 & $<0.001$ & $20.8(23.4)$ & $<0.001(.002)$ & $9.4(10.8)$ & $\begin{array}{l}0.947 \\
(.686) \\
\end{array}$ \\
\hline Nosocomial & 11.6 & & $27 \cdot 3$ & & 17.9 & & 21.0 & & $28.0(29.8)$ & & $9.8(9.7)$ & \\
\hline $\begin{array}{l}\text { Nosocomial other } \\
\text { admission }^{\mathrm{b}}\end{array}$ & 14.7 & & 32.2 & & 20.3 & & 18.7 & & $23.2(21.5)$ & & $9.8(9.3)$ & \\
\hline \multicolumn{13}{|c|}{ Hospital size (number of beds) } \\
\hline$<200$ & 8.5 & $<0.001$ & 25.6 & 0.012 & 13.7 & 0.016 & 15.6 & 0.038 & $24.0(26.6)$ & $0.238(.157)$ & $8.6(8.9)$ & $\begin{array}{l}0.007 \\
(.010) \\
\end{array}$ \\
\hline $200-500$ & 8.9 & & 25.4 & & 12.5 & & 16.4 & & $24.1(25.0)$ & & $8.2(8.4)$ & \\
\hline$>500$ & 11.9 & & 27.4 & & 16.6 & & 19.7 & & $26.7(29.0)$ & & $11.7(12.5)$ & \\
\hline \multicolumn{13}{|l|}{ Ward } \\
\hline Medical & 10.4 & $<0.001$ & 31.4 & $<0.001$ & 13.5 & 0.036 & 19.1 & $<0.001$ & $24.1(26.1)$ & $0.002(.001)$ & $12.4(13.4)$ & $\begin{array}{l}<0.001 \\
(<.001) \\
\end{array}$ \\
\hline Surgical & 9.5 & & 24.2 & & 13.1 & & 14.5 & & $22.6(22.8)$ & & $8.6(8.5)$ & \\
\hline Intensive care unit & 13.3 & & 27.0 & & 18.3 & & 23.1 & & $31.6(36.4)$ & & $10.3(11.6)$ & \\
\hline $\begin{array}{l}\text { Gynecology and } \\
\text { obstetrics }\end{array}$ & 4.4 & & 10.6 & & $4 \cdot 3$ & & 6.4 & & $22.9(23.3)$ & & $0.0(0)$ & \\
\hline Pediatric & 5.5 & & 5.4 & & 16.0 & & 2.9 & & $28.6(33.1)$ & & $2.9(3.1)$ & \\
\hline Other & 7.2 & & 32.6 & & 16.8 & & 30.5 & & $30.5(36.8)$ & & $16.9(18.4)$ & \\
\hline
\end{tabular}

${ }^{a}$ Numbers in parentheses are for Enterobacter cloacae.

${ }^{b}$ Patients hospitalised who, at the time of the survey, presented a nosocomial infection acquired during a previous admission in the same or other hospital. 
third-generation cephalosporins. For fluoroquinolones resistance, the factors found associated were age, hospital size, ward type and localisation of infection (Table 2).

Average of resistance for $E$. cloacae and $E$. aerogenes did not differ significantly (26.9\% vs $24.1 \%$, RR:1.12, $95 \% \mathrm{Cl}: 0.95-1.31$, and $10.1 \%$ vs $9.4 \%$, RR:1.08 95\% Cl:o.81-1.43, for resistance to third-generation cephalosporins and to fluoroquinolones respectively).

Regarding the main species of Enterobacter (E. cloacae) significant differences were found in rates of resistance to third-generation cephalosporins, for localisation of infection (highest in UTI, 32.4\%), nosocomial (29.8\%) and type of ward (highest in ICU, 36.4\%), and in rates of resistance to fluoroquinolones for increasing age, size of the hospital, localisation of infection

\section{FIGURE 1}

Annual use of fluoroquinolones and third-generation cephalosporins, Spain, 1999-2010

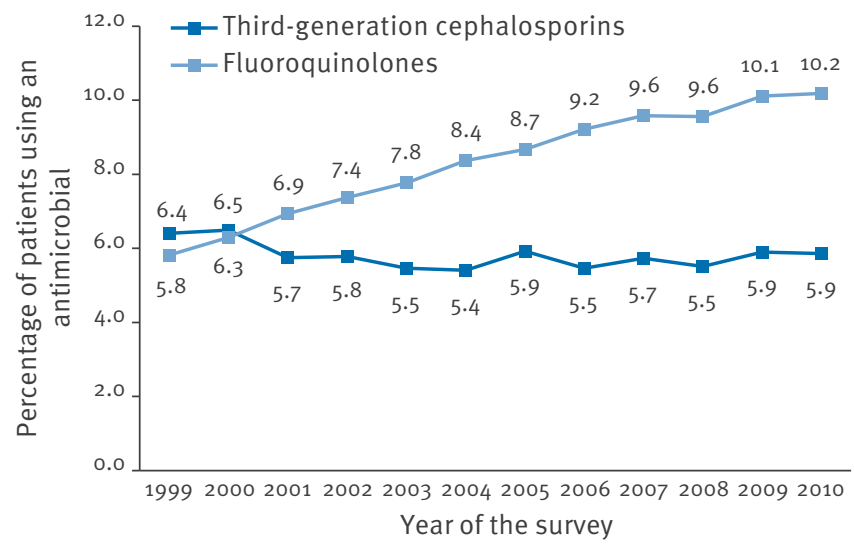

Use of fluoroquinolones or third-generation cephalosporins is defined as the number of patients receiving either type of antimicrobial per 100 patients on the day of the annual survey.

\section{FIGURE 2}

Annual rates of Enterobacteriaceae resistant to thirdgeneration cephalosporins, Spain, 1999-2010

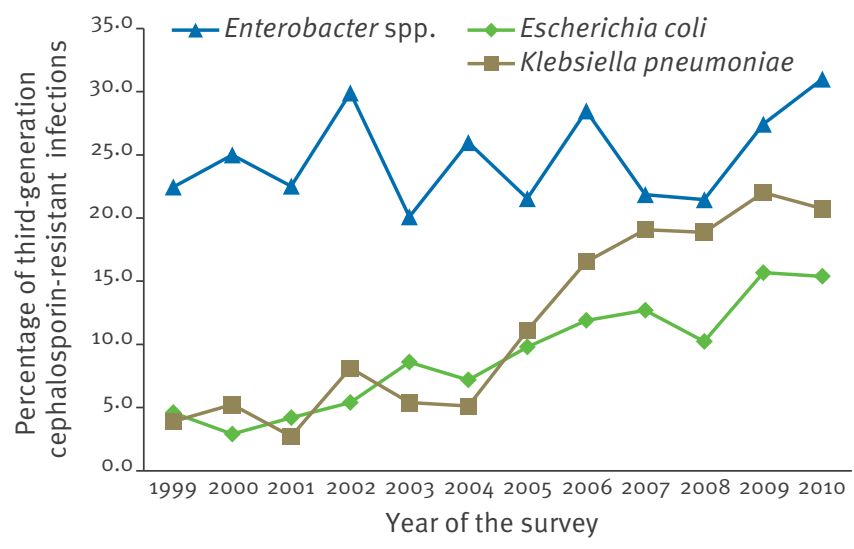

(highest in UTI, 16.2\%), and type of ward (highest in medical ward patients, $13.4 \%$ ) (Table 2).

Trends in antimicrobial use and resistance Antimicrobial use (number of patients receiving antibiotic/100 admitted patients) increased steadily for fluoroquinolones from $5.8 \%$ in 1999 to $10.2 \%$ in 2010 ( $p<0.001$ ), but no significant trend was observed for third-generation cephalosporins use (from $6.4 \%$ in 1999 to $5.9 \%$ in 2010) (Figure 1).

Proportion of resistance to third-generation cephalosporins increased significantly for $E$. coli infections (from $4.6 \%$ to $15.4 \%$, p<0.01) and for K. pneumoniae infections (from $3.9 \%$ to $20.8 \%$, p<0.01) with a more pronounced increase since year 2004. Nevertheless thirdgeneration cephalosporins resistance for Enterobacter spp. did not show a trend, and ranged from $22.5 \%$ to $31 \%$ with a mean rate of $24.3 \%$ (Figure 2 ).

Proportion of resistance to fluoroquinolones increased significantly for $E$. coli infections (from $15.9 \%$ to $29.6 \%$, p (0.01), and to a minor extent for Enterobacter spp. (from $6.4 \%$ to $14.9 \%$, p<0.01). For K. pneumoniae there was a great increase (from $5.5 \%$ to $22.4 \%$, p $<0.01$ ), also more pronounced since 2004 (Figure 3).

Proportion of co-resistance to fluoroquinolones and third-generation cephalosporins increased significantly for E. coli infections (from 1.6\% to $11.3 \%$, p $<0.01$ ), for Enterobacter spp. (from $4.8 \%$ to $9.5 \%$, p<0.01), and to a higher extent for $K$. pneumoniae infections (from $0.8 \%$ to $14.4 \%, p<0.01$ ) and more pronounced during the period from 2004 to 2007 (Figure 4).

We found strong correlations for rates of $E$. coli resistant to fluoroquinolones, resistant to third-generation cephalosporins, or co-resistant to third-generation cephalosporins and fluoroquinolones, by the rate of use of fluoroquinolones $(R=0.97, p<0.01 ; R=0.94$, $p<0.01$; and $R=0.96$, pro.01, respectively) (Figure 5A).

\section{FIGURE 3}

Annual rates of Enterobacteriaceae resistant to fluoroquinolones, Spain, 1999-2010

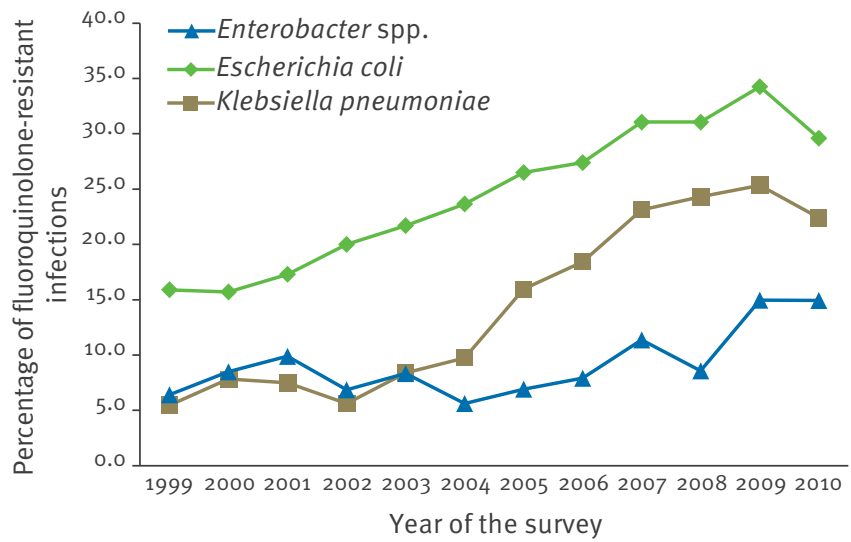


Also we found strong correlations for rates of $K$. pneumoniae resistant to fluoroquinolones, to third-generation cephalosporins, or co-resistant to third-generation cephalosporins and fluoroquinolones, by the rate of use of fluoroquinolones $(R=0.92, p<0.01 ; R=0.91$, p<0.01; and $R=0.92, p<0.01$, respectively) (Figure $5 B$ ), but these correlations could not be found by the use of third-generation cephalosporins. No significant correlations could be found for Enterobacter spp. resistant to third-generation cephalosporins and use of thirdgeneration cephalosporins or of fluoroquinolones. This was also the case for Enterobacter spp. resistant to fluoroquinolones and use of third-generation cephalosporins or fluoroquinolones.

\section{Discussion}

In the present study, we observed an increase in rates of resistance to third-generation cephalosporins and fluoroquinolones in the past twelve years in the main Enterobacteriaceae causing infections in hospitalised patients in Spain. This high rate of antibiotic resistance could increase the risk of inappropriate empirical therapy in hospitalised patients with potentially serious infections. In Spain, fluoroquinolones and thirdgeneration cephalosporins can be used empirically for both nosocomial and community-acquired pneumonias and UTIs. The increase in resistance to fluoroquinolones and third-generation cephalosporins nevertheless differed among Enterobacteriaceae representatives.

Enterobacter spp. (mainly E. cloacae) displayed the highest rates of resistance to third-generation cephalosporins and the rates did not increase over time, but by 2010 E. coli and K. pneumoniae isolates were 3.3 and 5.3 times more frequently resistant respectively than in 1999. The difference in resistance for Enterobacter spp. could be due to the fact that the main mechanism of resistance to third-generation cephalosporins for Enterobacter spp. is overproduction of AmpC betalactamases, whereas for $E$. coli and K. pneumoniae the main resistance mechanism is extended-spectrum

\section{FIGURE 4}

Annual rates of Enterobacteriaceae co-resistant to fluoroquinolones and third-generation cephalosporins, Spain, 1999-2010

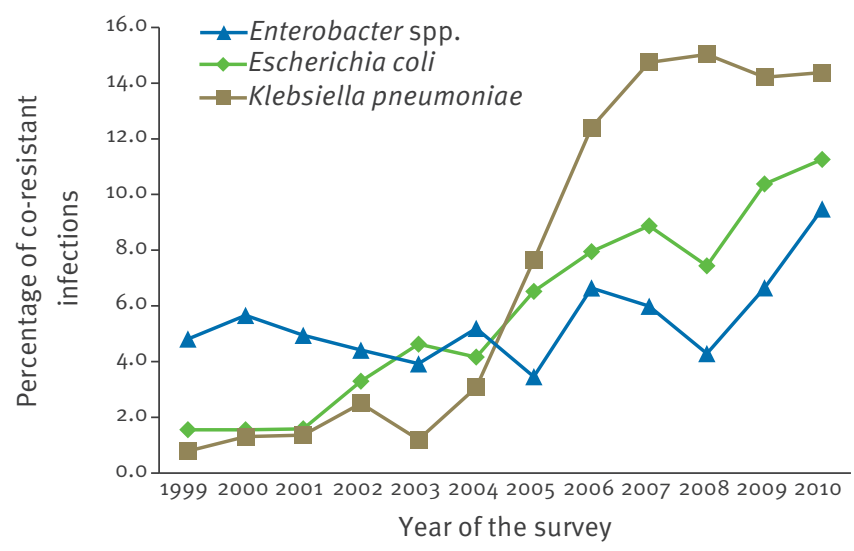

beta-lactamases $(\mathrm{ESBL})$ that has been related to antibiotic usage [9].

Overall, an increase in resistance to fluoroquinolones was observed for all three microorganisms reaching levels of resistance of $30 \%, 22 \%$, and $15 \%$, for $E$. coli, $\mathrm{K}$ pneumoniae, and Enterobacter spp. respectively. This tremendous increase in resistance was encompassed over the same time period by a $75 \%$ increase in the use fluoroquinolones in the hospitalised population. Furthermore, strong correlations were found for the use of fluoroquinolones inside the hospital and resistance to fluoroquinolones, to third-generation cephalosporins, or co-resistance to both groups of the latter antimicrobials for $E$. coli and K. pneumoniae. From a microbiological point of view, the increase of

\section{FIGURE 5}

Correlation between annual rate of fluoroquinolone use and resistance to fluoroquinolones, third-generation cephalosporins, or fluoroquinolones and third-generation cephalosporins, Spain, 1999-2010

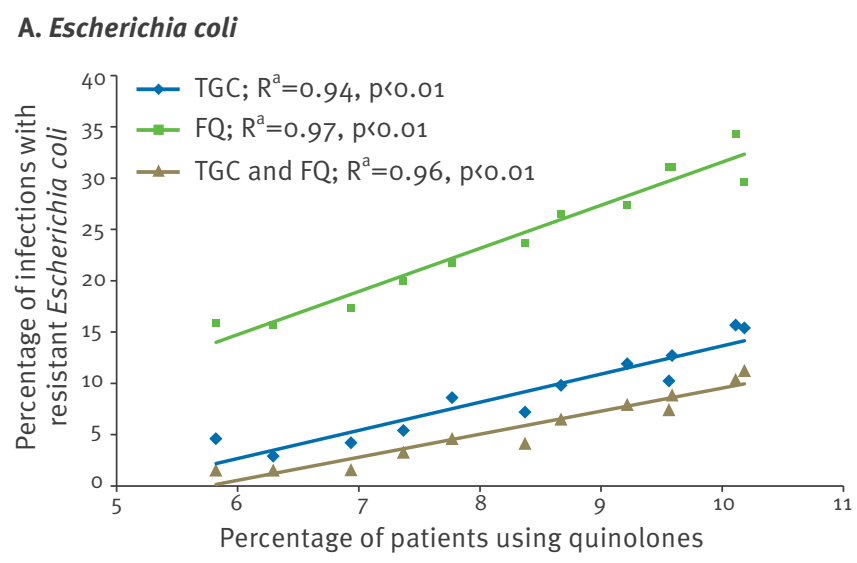

B. Klebsiella pneumoniae

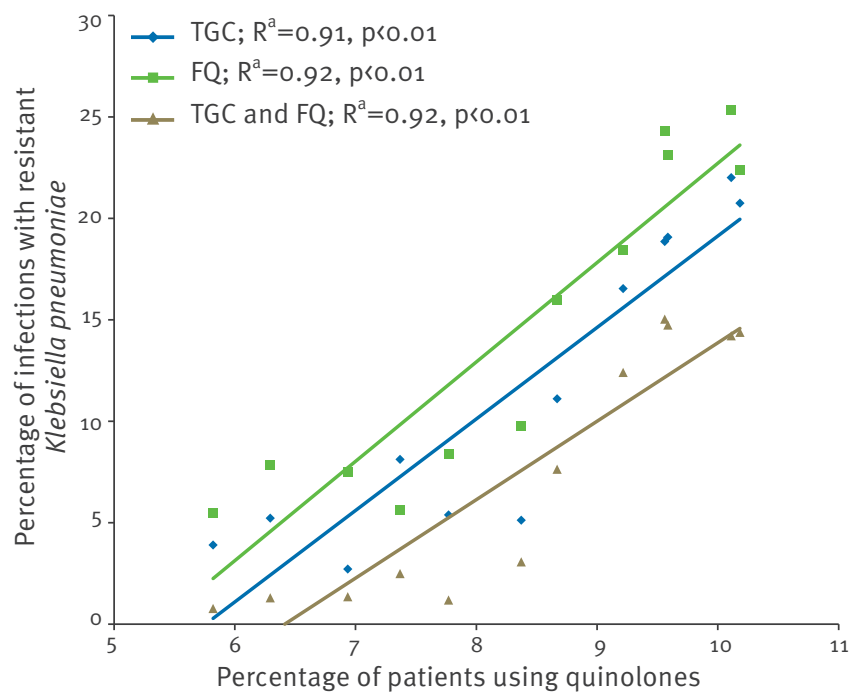

FQ: Fluoroquinolones; TGC: Third-generation cephalosporins.

a Pearson correlation coefficient. 
resistance to fluoroquinolones has been associated with mutations in the topoisomerases [10] and more recently by the acquisition of plasmid mediated fluoroquinolones resistance genes such as $q n r$, aac(6)- $/$ cr or qep particularly in ESBL producing isolates [11]. Although the use of third-generation cephalosporins did not increase over the time period surveyed, use of this antimicrobial was maintained. The continuing use of third-generation cephalosporins could have contributed to an increase in the rate of resistance of $E$. coli and $K$. pneumoniae to third-generation cephalosporins. In the hospital environment, the increase of fluoroquinolone use may also have allowed cephalosporinresistant Enterobacteriaceae to acquire additional resistance to fluoroquinolones. A co-selection process of co-resistance might have occurred [12].

In recent years, other studies have observed Spain as one of the countries in Europe with the highest use of fluoroquinolones outside the hospital [13]. This may have a role in co-selection and co-resistance, and potential clonal expansion influencing the results of this study. The observed differences in third-generation cephalosporin resistance among Enterobacteriaceae representatives could be related to the main resistance mechanism in the different studied bacteria (ESBL in $E$. coli and K. pneumonaie or AmpC hyperproduction in Enterobacter spp.) [14].

Not surprisingly, rates of resistance to third-generation cephalosporins were higher for ICU infected patients than on average, but the highest rates of fluoroquinolone resistance were found outside the ICUs (Table 2) probably related to the widespread use of this class of antimicrobial outside the ICUs.

It is important to note that resistance to antimicrobials can differ depending of the site of the infection. For $E$. coli the main resistance to third-generation cephalosporins was found in respiratory tract infections $(14.7 \%)$, infections that are rarely caused by $E$. coli outside the critical care units [15], a much higher rate than that for bloodstream infections (9.7\%, p<0.001). Nevertheless, for Enterobacter spp. the highest rates of third-generation cephalosporin resistance were found for bloodstream infections (29.1\%). Regarding resistance to fluoroquinolones the highest resistance in $E$. coli was for respiratory tract infections, while for K. pneumoniae and Enterobacter spp. was for UTI. It is important to keep in mind these differences when comparing to rates derived from a single site of infection.

It is also of note that for all these enterobacterial infections more than 50\% (56\% for E. coli and $41 \%$ and $36 \%$ for K. pneumoniae and Enterobacter spp., respectively) are community-acquired infections, that $88 \%$ of them are not bloodstream infections, and that looking for resistance only in nosocomial or bloodstream infections, in studies of antimicrobial resistance, can omit an important and valuable information for the development of prevention strategies.
Regarding co-resistance to both fluoroquinolones and third-generation cephalosporins, Enterobacter spp., $E$. coli and $K$. pneumoniae increased significantly their rates of co-resistance with time, but the most pronounced increase could be observed for $K$. pneumoniae reaching rates of co-resistance of almost $15 \%$ in the 2007-2010 period. It has been reported that many enterobacteria strains resistant to third-generation cephalosporins are also resistant to fluoroquinolone, and that this co-resistance could be mediated by plasmids harbouring both quinolone resistance and ESBL genes or presence of different plasmids harbouring these resistance genes [16]. It is remarkable that the greatest increase in co-resistance for these microorganisms, and to some extent for the resistance to fluoroquinolones and to third-generation cephalosporins, started around year 2004. These facts do not seem to be related to the antimicrobial use of fluoroquinolones or third-generation cephalosporins in hospitals, neither to any other fact known by us, and remains to be elucidated. It should be interesting to study the relationship of these facts with the consumption of other antimicrobial, such as amoxicillin-clavulanic, broadly used in Spain, since new formulations, for oral and parenteral routes, with increased dosage started to be marketed in Spain at the end of 2003.

To which extent rates of resistance derived from point prevalence studies can be overestimated when these rates of resistance are derived from an augmented length of infectious state attributable to antimicrobial resistance, needs further evaluation. When comparing data from our study to those reported by the European Antimicrobial Resistance Surveillance Network (EARSnet, formerly EARSS) for the period 2007-2009 in Spain, only slight differences were found (values for EARS-net and EPINE: non-suceptible E. coli to fluoroquinolones $32.3 \%$ vs $28.7 \%$, or to third-generation cephalosporins $9.5 \%$ vs $10.7 \%$, non-susceptible K. pneumoniae: to fluoroquinolones $17.2 \%$ vs $20.8 \%$, to third-generation cephalosporins $11.1 \%$ vs $16.0 \%$ ) [17]. Nevertheless, it should be taken into account that EARS-net records data to a net of national surveillance systems only on invasive infections, from voluntary clinical laboratories in Spain (between 29 to 33 and between 14 to 33 laboratories reporting for $E$. coli and K. pneumoniae, respectively), as opposed to the data from around 265 hospitals per year in EPINE, and that huge variations are found among laboratories reflecting wide local variations in rates of resistance [18].

There are some limitations for our study. As hospitals participated on a voluntary or compulsory basis, but were not selected at random, representativeness applies to regions where the study is mandatory but can not be warranted at the national level. On the other hand, this prevalence series represents more than half of the population hospitalised in acute care centres in Spain on a given day, and most data come from hospitals that have regularly participated in the survey every year so concerns about representativeness are 
diminished. Another limitation of our work is related to the non-experimental nature of the study so that to which extent this increase in antimicrobial resistance can be attributable to the increase in the use of fluoroquinolones cannot be concluded from the results of this ecological study but those results points out to this direction. One of the concerns about generalising our data is seasonality. As the survey was performed every year during May, seasonal variations in time could not be assessed. However, the fact that we performed the survey in the same season each year, although precluding a study of seasonality, allowed us to measure trends. Finally, point prevalence studies prove to be useful to monitor trends on rates of resistance and antimicrobial use at a national level, and can provide valuable information for comparisons among European Union Member States. Furthermore the information on antimicrobial use and resistance gathered by national prevalence surveys, linked to patient and infection characteristics, not focused exclusively on invasive infections, can complement that of much rigorous databases, from the microbiological point of view, such as EARS-net and could help to develop national strategies to prevention.

\section{Acknowledgments}

Supported by the Fondo para la investigación, Spanish Ministry of Health, grant Plo7/90255.

\section{The members of the EPINE network were:}

Andalucía: Antonia Gasch Illescas, Ma José Pérez Lozano, Miguel Gili Miner, Cristina Marín Estrada, Sebastián Expósito García, Francisco Jesús Reina Zamora, Francisco Calbo Torrecillas, Salvador de Oña Compan, María José de Torres García, Diego Román Rico, Joaquín Fernández-Crehuet Navajas, Victor Fuentes Gómez, Rafael Martínez Nogueras, M ${ }^{\mathrm{a}}$ Rosario Varela Escudero, Montserrat Gómez Olmedo, Lourdes Ballesteros García, Joaquín Bielsa Lázaro, José Francisco Guillen Solvas, María Amelia Fernández Sierra, María Amelia Fernández Sierra, Carmen Valero Ubierna, Amalia Ramos Cuadra, Fernando José López Fernández, Enrique Fernández Molle, Juan Bajo Arenas, Juan Antonio Zafra Mezcua, Jesús Dávila Guerrero, José Ignacio Blanco González, Mạ Pilar Fernández Antolí, José Antonio Ramírez Moreno, Carmen Díaz Molina, Segundo Dueñas Castro, Yolanda Ortega López, Carlos Javier Caballero Alonso, Miguel Porras Povedano, Alberto Cruz Broche, $M^{a}$ - Dolores Sureda Santiso, Gina Simonelli Muñoz, Maㅡ Angeles Lucerna Méndez, Ma Dolores Márquez Cruz, Ma Isabel Val Carrascón, Julián Manuel Domínguez Fernández. Aragón: Salvador Pastor Eixarch, Ma Jesús Hernández Navarrete, Carlos Lapresta Moros, Ma Piedad Stoduto García, Carlos Aibar Remón, Salvador Pastor Eixarch, $M^{a}$ Jesús Zamora Rodríguez, Juan Rodríguez García, Ana María Cortés Ramas, Rafael Fernández Santos, Carmen Navarro Pardos. Asturias: Juan Caunedo del Potro, Mónica Fernández Fernández, Gerardo Rubiera López, Pilar Prendes Peláez, Maㅡ Teresa Iglesias Cueto, Pedro Abad Requejo, Lucía Barreiro Hurle, $M^{\underline{a}}$ del Mar Martínez Suárez, Maㅡ Eugenia Llaneza Velasco, Fernando Vázquez Valdés, Covadonga García-Bobia Fernández. Balearic Islands: Olga Hidalgo Pardo, Antonio Pareja Bezares, Margalida Fortuny Esbert, Margalida Fortuny Esbert, Julia Troya Casero, Javier Sánchez, Lluis Carbó Saladrigas. Canary Islands: Anna Quori, Teresa Montserrat Blasco, Domingo Panizo Rivas, Pedro Barrera Díaz, Ricardo Cerrudo Hernández, Néstor Rocío Pérez,
Jezabel García Yanes. Cantabria: Jesús Ricardo Mozota Ortiz, Juan Antonio Sanz Salanova, Mạ Concepción Fariñas Álvarez. Castilla-La Mancha: Enriqueta Muñoz Platón, Amaya Biurrun Larralde, Isidoro Salamanca Carranza, Máxima Lizán García, Juan Sanz Cortés, Ma Victoria Caballero Martinez, Isidoro Salamanca Carranza, Inés Sánchez Ruiz, Ma Rosario Sánchez Blanque, Carmen Romero Portilla, Mar Gómez Santillana. Castilla y León: Nieves Coladas Rodríguez, Maㅡ Belén Cantón Alvarez, Ma del Carmen Sáenz González, Juan Gastelu-iturri Bilbao, Juan Gastelu-iturri Bilbao, Guillermo Fernández Quintana, Ma - Sonsoles Paniagua Tejo, Javier Lozano García, Evaristo Arzalluz Ruiz, Carmen Gimeno Crespo, Carlos Carrillo Sarabia, Elva Valdés Vázquez, José Manuel Alvarez Alonso, Marta Eva González Pérez, Isabel García Palomar, Ma Soledad Martínez Sáez. Catalonia: Josep Vaqué Rafart, José Ma Sánchez García, Magda Campins Martí, Antoni Trilla García, Mercè Gurguí Ferrer, Ma Dolors Salvia Roigés, Lourdes Ferrer Ruscalleda, Raimon Camps i Salat, Mireia Urrea Ayala, Vicens Díaz de Brito Fernández, Joaquín Martínez Montauti, Martina González Vázquez, Ana Lérida Urteaga, Irma Casas García, Ma Ángeles Morcillo Rodríguez, Alejandro Smithson Amat, Elena Espejo Arenas, Fco. Javier Gurri Hernández , Lluís Falgueras López, Pilar de la Cruz Solé, Lluís Moner Coromina, Lluís Force i Sanmartín, Nuria San Juan Martínez, Dolors Mas Rubio, Rafel Pérez Vidal, Ferran Pastor Solernou, Francesc Báguena Escolano, Angeles García Flores, Oscar del Río Pérez, Jordi Cuquet Pedragosa, Elisabeth Mauri Nicolás, Josep Vilaró i Pujals, Carles Orta Sagalàs, Marta Lora Díez, Ma Lluïsa Urcola Piñol, Antonio Radovan Gonçalves, Josep Bisbe Company, Paula Gassiot Cordomí, Teresa Aliu Bou, Guadalupe Serrate San Miguel, Fernando Bercenilla Gaite, Irene Montardit Bertral, Gabriela Picco, Montse Olona Cabases, Xavier Raga Luria, Josep M ${ }^{a}$ Calbet Vidal, Antoni Castro Salomó, Montserrrat Nolla Avila, Josep Rebull Fatsini, Montserrat Camps Gallart.. Extremadura: Antonio Cerrillo Cruz, María José Luque Calderón, María Carmen Gómez Gonzàlez, $M \stackrel{\text { a }}{ }$ Rosario Sánchez Benito, Juan Felipe Alvarez García, José Miguel García Garraus, María Carmen Gómez Gonzàlez, Isaías Montes Martínez. La Rioja: Cristina Belío Blasco, Mํㅡㄹ Teresa Jiménez Buñuales. Galicia: Juan J. Gestal Otero, José Miguel Fernández Naveiro, Jose Manuel Suárez Lorenzo, Ángela Varela Camino, Pablo Asensio Hernández, Ma Virginia Lorenzo García, Jorge Pérez Carracedo, María Jato Díaz, Berta María Uriel Latorre, Ramona Suárez Soto, Margarita Cueto Baelo, Jorge Cavero Zamorano, $M^{\mathrm{a}}$ Angeles Bouzas Rodríguez, Victor Miguel del Campo Pérez, Susana Alonso Bürger, José Carlos Quintas Fernández, Luisa Abaira Garcia, Juan José González Soler. Madrid: Verónica Pérez Blanco, Ignacio Gadea Gironés, Angel Asensio Vegas, Ma Paz Rodríguez Pérez, Sonia de Miguel Fernández, María Beatriz Pérez Gorricho, Pedro Luis Romera Garrido, Leonor Antolín Manuel, Felisa Jaén Herreros, Ildefonso González Solana, Juan Martínez Hernández, Daniel Trocoso Viejo, Olga Rodríguez González, Tomás Colón Bombin, José Lorenzo Valencia Martín, Leonor Antolín Manuel, Cornelia Bischofberger Valdés, Leonor Antolín Manuel, Leonor Antolín Manuel, Ana Chiaraviglio Arévalo, Belén Martínez Mondéjar, Nieves López Fresneña, $M^{a}$ - Teresa Sayalero Martín, Isabel Viúdez Jiménez, Susana de Juan García, Elena García Puente, José Ramón Villagrasa Ferrer, Lourdes Sainz de Los Terreros Soler, $M^{\underline{a}}$ Dolores Vigil Escribano, Cristina García Fernández, Francisco Javier Gracia San Román, Lidia Aranzábal Orgaz, Amalia Urmeneta Rada, Susana de Juan García. Murcia: Francisco Botía Martínez, Rosa Ma Blázquez Garrido, Pilar Jiménez Fernández, Mar Alcalde Encina, Francisco Javier Campayo Rojas, Gerardo Alonso Garcia, Guillermo F. Alguacil García, Ma Luisa López Yepes, Margarita Cámara Simón, Antonio Martínez Blázquez. Navarra: Federico Repáraz Abaitua, Ma Teresa Ortega Maján, Judith Chamorro Camazón, Francisco Guillén Grima, Eduardo Layana Echezuri. Comunidad Valenciana: Alicia Hernández Galve, Empar Carbonell Franco, Mayte Murillo, Rafael Manuel Ortí Lucas, Ma Dolores Gil Aparicio, José Luís Alfonso Sánchez, Nieves Aparisi Valero, Vicente Zanón Viguer, Sergio Fernández Martínez, Fernando 
Gómez Pajares, Edith Leutscher, Adela Martínez Martínez, Carles Mayordomo i Fernández, Carlos Emilio Oltra Alcaraz, Rosa Romana Manrique Blázquez, Ana González Ros, Pilar Montesinos Butrón, José Tuells, Victoria Valls Jiménez, Antonio González Torga, Juan Francisco Navarro Gracia, Jesús Maa Aranaz Andrés, Maribel Bermúdez, Alberto Cabrera Quintero, Juan Manuel Beltrán Garrido, Rita Holguín Gómez, Vicenta Rodrigo Bartual, $M^{\underline{a}}$ Carmen Adell Aparicio, Dolores Ferrer Evangelista, Leopoldo Segarra Castelló. Euskadi: José Luis Novales Salcedo, Ma del Carmen Rosario Gómez-Pérez de Mendiola, José Ramón Sáenz Domínguez, Jorge Taboada Gómez, Maㅡ Hortensia Esparza Muñoz, Higinio Gómez Martín, José Ignacio Villate Navarro, Itziar Lanzeta Vicente, José Antonio Jiménez Alfaro, Marta Alvarez de Arcaya, Margarita Viciola García, José Luís Díaz de Tuesta, Mạ del Rosario Antoñana Ozaeta, Ma Mercedes Gabari Machín, Fernando Collado Nicolás, José Ramón Sáenz Domínguez, Pedro María Sagredo Franco.

\section{References}

1. Paterson DL. Resistance in gram-negative bacteria: Enterobacteriaceae. Am J Med. 2006;119 (Suppl 1):S20-8.

2. Luzzaro F, Viganò EF, Fossati D, Grossi A, Sala A, Sturla C, et al. Prevalence and drug susceptibility of pathogens causing bloodstream infections in northern Italy: a two-year study in 16 hospitals. Eur J Clin Microbiol Infect Dis. 2002;21(12):849-55.

3. Gaynes R, Edwards JR, National Nosocomial Infections Surveillance System. Overview of nosocomial infections caused by gram-negative bacilli. Clin Infect Dis. 2005;41(6):848-54

4. Podschun R, Ullmann U. Klebsiella spp. as Nosocomial Pathogens: epidemiology, taxonomy, typing methods, and pathogenicity factors. Clin Microbiol Rev. 1998;11(4):589-603.

5. Rammelkamp M. Resistance of Staphylococcus aureus to the action of penicillin. Proc Soc Exp Biol Med. 1942;51:386-9.

6. Garner JS, Jarvis WR, Emori TG, Horan TC, Hughes JM. CDC definitions for nosocomial infections, 1988. Am J Infect Control. 1988;16(3):128-40.

7. Hawser S, Badal RE, Bouchillon SK, Hoban DJ, Hsueh PR. Comparison of CLSI 2009, CLSI 2010 and EUCAST cephalosporin clinical breakpoints in recent clinical isolates of Escherichia coli, Klebsiella pneumoniae and Klebsiella oxytoca from the SMART Global Surveillance Study. Int J Antimicrob Agents. 2010;36(3):293-4.

8. Clinical Laboratory Standards Institute (CSLI). Performance standards for antimicrobial susceptibility testing. 2oth International Supplement M100-S20. Wayne (PA): CLSI, Jan2010. Available from: http://www.clsi.org/source/orders/ free/m100-s20.pdf

9. Arnan M, Gudiol C, Calatayud L, Liñares J, Dominguez MÁ, Batlle $M$, et al.Risk factors for, and clinical relevance of, faecal extended-spectrum $\beta$-lactamase producing Escherichia coli (ESBL-EC) carriage in neutropenic patients with haematological malignancies. Eur J Clin Microbiol Infect Dis. 2011;30(3):355-60.

10. Morgan-Linnell SK, Becnel Boyd L, Steffen D, Zechiedrich $\mathrm{L}$. Mechanisms accounting for fluoroquinolone resistance in Escherichia coli clinical isolates. Antimicrob Agents Chemother. 2009; 53(1):235-41.

11. Robicsek A, Jacoby GA, Hooper DC. The worldwide emergence of plasmid-mediated quinolone resistance. Lancet Infect Dis. 2006; 6(10):629-40.

12. Cantón R, Ruiz-Garbajosa P. Co-resistance: an opportunity for the bacteria and resistance genes. Curr Opin Pharmacol. 2011;11(5):477-485.

13. Ferech M, Coenen S, Malhotra-Kumar S, Dvorakova K, Hendrickx E, Suetens C, et al. European Surveillance of Antimicrobial Consumption (ESAC): outpatient antibiotic use in Europe. J Antimicrob Chemother. 2006;58(2):401-407.

14. Szabo D, Silveira F, Fujitani S, Paterson DL. Mechanisms of resistance of bacteria causing ventilator-associated pneumonia. Clin Chest Med. 2005;26(1):75-9.

15. Joseph NM, Sistla S, Dutta TK, Badhe AS, Rasitha D, Parija SC. Ventilator-associated pneumonia in a tertiary care hospital in India: role of multi-drug resistant pathogens. J Infect Dev Ctries 2010;4(4):218-25.

16. Schwaber MJ, Navon-Venezia S, Schwartz D, Carmeli Y. High levels of antimicrobial coresistance among extendedspectrum-beta-lactamase-producing Enterobacteriaceae. Antimicrob Agents Chemother 2005;49(5):2137-9.
17. EARS-net. [Accessed 2 Aug 2011]. Available from: http://www. ecdc.europa.eu/en/activities/surveillance/EARS-Net/Pages/ index.aspx

18. Antimicrobial Resistance Surveillance Network (EARS-Net). Annex 2: Country summary sheets. Spain. In: Antimicrobial resistance surveillance in Europe 2009. Annual Report of the European Antimicrobial Resistance Surveillance Network (EARS-Net). Stockholm: European Centre for Disease Prevention and Control (ECDC); 2010:178-81. [Accessed 2 Aug 2011]. Available from: http://ecdc.europa.eu/en/publications/ Publications/1011_SUR_annual_EARS_Net_2009.pdf 